\title{
The Application of Content-based Instruction to Tourism English Audio-Oral Teaching
}

\author{
Xin $\mathrm{Li}^{1, \mathrm{a}}$ \\ ${ }^{1}$ Hanjiang Normal University, Shiyan, Hubei Province, China \\ a549404542@qq.com
}

\begin{abstract}
Keywords: Content-Based Instruction; Listening And Speaking For Tourism English; Teaching
\end{abstract} Effect.

\begin{abstract}
With the development of tourism English, the demand of the market for international tour guide becomes higher. However, the teaching of tourism English cannot meet the demand of the market. Content-based instruction combines language teaching with subject content. It organizes teaching activities according to subject content, which can stimulate the students' interest and internal motivation, improve the students' autonomous learning ability and teaching effect and cultivate the students' vocational ability and teamwork spirit.
\end{abstract}

\section{Introduction}

The tourism industry has rapidly developed especially China's entry and exit tourism industry. Therefore, the tourism market has put forward higher requirements for the practitioners. They should not only have a good knowledge of tourism management, but also have higher English communication ability. Foreign tour guides should have higher communicative competence and oral English. However, the curriculums of Higher Vocational Tourism English still adopt traditional teaching methods. They focus on systematic knowledge instead of practice and oral English, which cause that the students cannot flexibly apply the learned knowledge of the English language. It is difficult to achieve the target of effective communication with English in the future occupation and it is lack of professional skills. Therefore, in the current English listening and speaking teaching in higher vocational colleges, it is urgent to change the original teaching philosophy, introduce the new teaching modes and teaching methods, which can change the current situation.

\section{Content-based Instruction}

The definition of Content-based Instruction and its theoretical basis go as follows. Content-based instruction arose in the western world in 1960s. During its developing process, different scholars at home and abroad defined this concept differently. In this article, the definition from Richards \& Rodgers (2001) is used. "Content-based instruction is a method using in second language teaching. It advocates class organization should be based on the content or information which needs to be obtained by students, rather than based on linguistics or other kinds of teaching syllabus." [1] Briefly speaking, the content-based instructions a kind of teaching concept rather than teaching method. It insists that the acquisition of language is the medium of subject content learning. The direct goal of study is the learning of content rather than the mastering of language.

Constructivist Learning Theory, together with Krashen's theory of Second Language Acquisition and Input Hypothesis Theory, has laid a solid theoretical foundation for content-based instruction. Scholars who hold Constructivism Constructivist Learning Theory believe that, students should learn through a real, meaningful language context, and through the meaning construction method. Content-based instruction provides foreign language learners with a real and meaningful language environment, and helps them to organize class activities on the basis of topic's content. Krashen believes that the "sheltered subject-matter teaching" is the most effective method for foreign language teaching [2]. 
Common methods and features of content-based instruction include the following aspects. Based on the differences of teaching targets, content-based instruction can be divided into Theme--based Instruction, Sheltered Subject Matter Instruction, Adjunct Instruction and so on [3]. The division of content-based instruction methods is in accordance with the diminishing attention on content and the increasing attention on the language. This classification can help teachers to comprehend the connotation of the content-based instruction better. As to the question of choosing proper models for actual teaching practice, the answer should be various with specific circumstances. Only the expedient, flexible patterns which do not stubbornly follow the specific requirements of one particular method can truly implement the concept of content-based instruction, and tends to achieve better teaching effects [4].

This article explores the application of theme--based instruction to tourism English audio-oral teaching in higher vocational school. Theme-based instruction emphasized that foreign language teaching activities should be organized on the basis of subject content or the topic of information which needs to be learned by the students. It used language as the medium to learn knowledge. According to the requirements of students' learning ability and mental status, language learning should be combined with real, meaningful content or information. The focus of teaching needs to be transferred from language learning to master professional skills and subject content.

Foreign language class organized under the guidance of content-based instruction goes as follows. The topic is determined based on real, meaningful materials; then the students are being asked to conclude and understand related information, and do well in language learning in this process. These materials provide students with a platform to practice their listening and speaking skills, while the practice of listening and speaking abilities offers them a chance to summarize and use the subject content. Therefore, advantages of content-based instruction's application to tourism English visual-audio-oral teaching are obvious.

\section{Problems Existing in Current Tourism English Audio-Oral Classes}

Firstly. According to the information gathered through student interview and the author's recording of tourism English class in Yunyang Teachers' College for a semester, current tourism English audio-oral class in higher vocational school still adopts the traditional teacher-centered mode, although the teachers have combined a variety of teaching methods. In the class, the teacher explains knowledge first, then students do group practice: that is the students' language output process. The teacher takes a dominate role in this process, while the learning enthusiasm of students do not activated properly. Students are passive learners in class. These teaching concepts are relatively outdated. And the new teaching concepts which are beneficial to the students need to be introduced.

Secondly. Students' academic bases are relatively weak in higher vocational colleges; especially in English, let alone their listening and speaking skills. In addition, students' learning motivation is not strong, and they are lack of initiative spirits. Therefore, teachers should update their teaching concepts and optimize their teaching methods to activate students' learning interest and initiative learning spirits.

Thirdly. In tourism English audio-oral classes, a plenty of specialized vocabulary about tourism is involved. Such as words relates to "preparation before landing". The text of a listening material named "Instruction on the Declaration" deals with a number of specialized vocabularies in custom declaration form. Students' output in oral English and comprehension of listening articles are often affected by their insufficient vocabulary reserve. Therefore, the enlargement of specialized vocabulary in tourism English is an important way to improve tourism English curriculum, while the specialized vocabulary should be acquainted in the process of learning tourism professional knowledge. That consists with the core idea of the content-based instruction.

All in all, the reformation of tourism English audio-oral classes should be achieved imminently. The content-based instruction focuses on students' cognitive and psychological needs, and it uses real, meaningful materials, deploys various teaching methods flexibly. Students can acquire new information and explore new knowledge on the basis of their existing knowledge system. This kind of teaching, which uses language learning as the tool of content learning and consider content learning 
as the goal of language learning, can meet the requirements tourism English audio-oral classes in higher vocational school.

\section{The Application of Content-based Instruction to Tourism English Audio-Oral Teaching}

In 1997, Stoller \& Grabe put forward the "six Ts" method. "Six Ts" represent themes, texts, topics, threads, tasks and transitions [5]. "six Ts" method is a more specific curriculum guidance. Grouping the real, meaningful teaching materials into several themes should be based on the students' interests and language abilities. Each theme can be subdivided into several sub topics. Organizing teaching activities based on the tasks (subject content), making the students master the professional knowledge of tourism management and improve the level of their English speaking and listening at the same time. Based on the core concept of content-based instruction, the writer analyzes the application of content-based instruction to tourism English audio-oral classes from the following aspects.

Firstly, the themes. In the class, the theme should be determined on the basis of students' interests, their language abilities and cognitive development levels. The teaching material named "Tourism Visual-Audio English" divides its contents according the six elements of tourism: transportation, lodging, eating, tour, shopping and entertainment. According to different themes, the teacher can take students to companies which joins the university-enterprise cooperation program, such as a four-star hotel or travel agency, to do the field research. Ask students to collect the first-hand materials, and organize the data combined with actual work requirements. In the class, students do the role-play according to their sorted data, trying to simulate the real working scene. In that way, students are more easily to digest the professional knowledge on tourism and can master the English language better. This method not only cultivates students' initiative learning ability, but also fosters their team cooperation spirit.

Secondly, the texts, or the subject content. It includes teaching materials and related exercises, as well as audio materials like video and film data, reading materials like magazines and newspapers, work places like training rooms and practice bases. Modification of material's content should be done by the teachers according to the requirements of themes. Part of obsolete materials and materials with English language which is too difficult to students should be cut, while materials which are interesting or associated with real life should be added. In this way, the texts can comply with students' English level and stimulate their learning interest. It helps students to learn initiatively and improve teachers' teaching effect.

Thirdly, the topics. Topics are more detailed, in-depth explorations of themes based on content. The same theme can be divided into different topics, while the detailed learning and more in-depth inquires can be achieved through different topics. For example, the first theme of "Tourism Visual-Audio English" is transportation. The teacher can subdivide it into transportation by plane, by train and by ship. In the classroom, students can be required to design topics about different means of transportation, and to perform scenario simulation accordingly. These three topics together constitute the theme of "transportation". The theme is divided into topics, and students can learn the theme step by step. These activities lessens students' fearfulness on the difficulty of English learning, meanwhile cultivates their self-confidence and initiative learning enthusiasm. Therefore, the teacher can get good teaching results and feedback.

Forth, the threads. In order to reflect the relevance of curriculum, the threads are used to combine different themes. Take "Tourism Visual-Audio English" as an example. The book is divided into six themes: transportation, lodging, eating, tour, shopping and entertainment. The thread of these six themes is the elements of tourism. They are classifications of the integrations of tourism elements. The thread of tourism elements combines these six themes together, and reflects the systematic, organized teaching. The thread is also an standard to select teaching materials. It helps teachers to select materials with pertinence. Under the guidance of the scientific framework, teachers can organize the teaching activities with certain purposes.

Fifthly, the tasks. Briefly speaking, the tasks are teaching activities designed based on subject content. The target of tourism English audio-oral classes is to cultivate students' listening and speaking skills, but the tasks can not be designed with utilitarianism to realize this goal. Tourism 
English audio-oral classes should be designed on the basis of specialized knowledge in tourism, trying to make students grasp specialized knowledge. At the same time, teachers need to design tasks to improve students' listening and speaking skills. Teachers can provide students with simulation scenarios of all kinds of working scene in hotels and travel agencies, and help students to improve their listening and speaking abilities in these real, meaningful scenarios. These tasks help the teacher to achieve teaching effect twice with half the effort. Moreover, they offers students the real experience of creatively study and apply, as well as the experience of applying their knowledge into usage.

Sixthly, the transitions. Transitions refer to these clever connections between different themes. Themes are key to content-based instruction, and the threads combines different themes together. Transitions deal with questions like how to combine different themes, and which kinds of methods should be used to lead students transit from one theme to another. Transitions are equivalent to the introductions of new lessons. Natural, novel transitions, like introductions, can help students to move on to the next topic naturally without abruptness. They can also help to hold students' learning interests. If the teacher uses a good transition, students will be eager to learn new knowledge, and at the same time they can review the old knowledge, and learn the new knowledge through their precedent knowledge system. In this way, the teaching results can be unexpected good and expected goal can be achieved.

\section{Conclusions}

Content-based instruction is a kind of teaching mode which combines language learning and content learning. This paper explores the application of this teaching mode in tourism English listening and speaking course. The teaching philosophy of this content-based instruction is to apply tourism professional content as English language learning, which helps the students to create real working environment, complete the tasks while comprehensively using language and tourism knowledge, improve the students' ability in the real working environment with effective communication. It is an effective teaching mode of learning tourism knowledge and improving English language ability of listening and speaking.

\section{References}

[1] Richards J.C. \& Rodgers, T.S. Approaches and Methods in Language Teaching. Cambridge University Press, 2001.

[2] DAI Qing-ning \& LV Ye. Content-based Instruction and Its Prototype Program Models [J]. FOREIGN LANGUAGE TEACHING, 2004 (4): 16-20.

[3] HAO Li-na. Design of Higher Vocational College English Curriculums based on Theme-based Content Teaching Mode [J]. Journal of Language and Literature, 2011 (11).

[4] LI Li-li. Application of CBI in the Jewish American Literature Course [J]. Heilongjiang Researches on Higher Education, 2015 (2).

[5] Stoller, F. L. \& Grabe, W. A Six-T's Approach to Content-Based Instruction [G]. // In Snow, M. A. \& Brinton, D. M. (eds). The Content-Based Classroom: Perspectives on Integrating Language and Content. New York: Longman, 1997. 